\title{
POLYPILL ADMINISTRATION IS IT MANDATORY FOR CARDIOVASCULAR DISEASE PREVENTION?
}

\section{Dr. Nirmal Garbadu MD (Med), Senior Consultant, Health Care Cuttack}

\section{KEYWORDS :}

Cardiovascular diseases (CVD) are an important global health challenge and a leading preventable risk factor for premature death and disability worldwide. Management or prevention of CVD is typically carried out in two stages-

\section{- Primary prevention of CVD}

- Secondary prevention of CVD

Primary prevention for CVD is defined as individual or community actions targeted to a population with risk factors, but without the presence of the disease. The individual approach involves screening vulnerable patients. While the main goal of secondary prevention is to decrease morbidity and mortality through programs that use effective pharmacological strategies ${ }^{1}$. A high proportion of CVD deaths occurs in people who already had an event and, in these individuals, mortality can be reduced with appropriate pharmacological and lifestyle management ${ }^{2}$. The World Health Organization (WHO) recommends that for secondary cardiovascular prevention in patients (individuals who have had a heart attack or ischemic stroke) should, in addition to lifestyle changes, take an antiplatelet agent, statin, and blood-pressure-lowering drugs for the long term, to reduce the risk of a recurrent nonfatal or fatal CVD events ${ }^{3}$. However, it has been observed that increasing the number of drugs, decrease the patients' adherence to these cardiovascular (CV) treatments. Poor adherence to multidrug regimens is a common and major barrier to effective therapy ${ }^{4}$. Also, most people do not take these drugs long term i.e., poor adherence to pharmacological treatment ${ }^{5}$.

Essentially, polypharmacy is highly recommended and essential in CVD care, consequently, fixed-dose combination therapy seems to be an intervention that has the potential to substantially enhance access and adherence to multidrug therapy by making recommended medicines more accessible in $\mathrm{CVD}^{6}$. Further, the simplification of fixed-dose medications by using a single 'polypill' is an attractive strategy to improve adherence to medications and therapy. A polypill is a medication that combines multiple active pharmaceutical ingredients ${ }^{1}$. The concept of polypill is based on the findings from the clinical study by Wald and the group. Wald et al reported that combination pharmacotherapy (CP) in a single pill or Polypill ${ }^{\mathrm{TM}}$ can reduce the incidence of coronary heart disease (CHD) by $88 \%$ and stroke by $80 \%$ if taken by all persons aged $\geq 55$, as well as the person of any age with existing CVD or diabetes ${ }^{7-9}$. It has been hypothesized that although these drugs are largely proven to be efficacious independently when prescribed together their effects remain independent such that they may reduce the risk of future CVD events by well over $50 \%{ }^{4}$. In the prevention of CVD, the types of treatment to which the term "polypill" refers can be classified into three groups:

A. Single-pill combinations containing aspirin, a statin and blood pressure (BP)-lowering agents mainly focused on prevention and treatment in patients with established atherosclerotic CVD;

B. Fixed-dose combinations (FDCs) containing three or four BP-lowering medications at low doses; and

C. Two-drug or three-drug combinations currently on the market, such as two-drug combinations of a BP-lowering drug and a statin, metformin and a statin, and other combinations.
The role and components of a polypill for the secondary prevention of CVD are different from - and currently more clearly defined than - those of a polypill for the primary prevention of CVD. A polypill for the secondary prevention of CVD should include a statin, -blocker and aspirin, and probably higher doses of at least some of the components. The case for a polypill for the secondary prevention of CVD is mainly for convenience, which is expected to promote adherence to the therapy ${ }^{1}$.

The World Heart Federation (WHF) identifies the use of the first category of polypills for CVD as a central part of their strategy for the secondary prevention of CVD to achieve their target of reducing premature mortality from non-communicable diseases by $25 \%$ by the year 2025 . The work of the WHF has been backing the inclusion of polypills for CVD on the WHO List of Essential Medicines and aligning it with initiatives to improve access to medicines for non-communicable diseases. The use of polypills in the secondary prevention of CVD has received broad support; however, the use of polypills in the primary prevention of CVD is more controversial. Patients should be prescribed the components according to best medical practice, but providing these components in a combined polypill format simplifies the administration of therapy and improves therapy adherence ${ }^{1}$.

The utility of polypill in the primary prevention strategy was studied in the large, Phase II randomized TIPS-1 (Indian Polycap Study-1) ${ }^{12}$. This study assessed the effects of different pills containing either single agents or combinations of drugs to measure their effect on risk factors, such as BP and lowdensity lipoprotein cholesterol (LDL-C). It was found that patients randomized to the polypill group exhibited BP reductions similar to those assigned to three BP-lowering drugs and lower LDL-C reductions compared with those receiving simvastatin alone. Also, the tolerability of the polypill was similar to that of other treatments, regardless of the number of active components in the one pill. The PILL (Program to Improve Life and Longevity) study also reported similar findings in 378 subjects $^{13}$. However, for secondary prevention, TIPS-2 (Second Indian Polycap Study) reported a significant reduction in BP and LDL-C in patients with stable CVD or diabetes with the use of the combination drugs used in TIPS-l. The polypill containing three BP-lowering drugs viz., atenolol $50 \mathrm{mg}$, hydrochlorothiazide $12.5 \mathrm{mg}$, and ramipril 5 $\mathrm{mg}$, along with simvastatin $20 \mathrm{mg}$, and aspirin $100 \mathrm{mg}$ were given in the trial. The investigators anticipated that the fulldose regimen would reduce the risk of CHD by $75 \%$, and stroke by $65 \%{ }^{14}$. Use of a Multidrug Pill In Reducing Cardiovascular Events(UMPIRE) study was the first randomized trial designed to assess the long-term effect of a polypill strategy in improving patients' adherence to medication in CV prevention ${ }^{15}$. The study included 2,004 patients (88\% with CVD) from 3 European countries and India. Patients were randomly assigned to the polypill strategy or usual care. Two different polypill strategies were used at the physicians' discretion: aspirin $75 \mathrm{mg}$, lisinopril 10. $\mathrm{mg}$, simvastatin $40 \mathrm{mg}$, and either atenolol $50 \mathrm{mg}$ or hydrochlorothiazide $12.5 \mathrm{mg}$. At the end of the study (median follow-up 15 months), adherence to medication in the polypill 
group was $85 \%$ compared with $60 \%$ in the standard care group ( $p<0.001$ ). BP and LDL-C levels were reduced with the polypill strategy to a greater extent than with standard care, but the differences were modest $(2.6 \mathrm{~mm} \mathrm{Hg}$ and $4.2 \mathrm{mg} / \mathrm{dl}$, respectively; $\mathrm{p}<0.001$ for each). No significant differences were reported in the incidence of serious adverse effects between the groups ${ }^{15}$. Similar findings were reported in the IMPACT (Improving Adherence Using Combination Therapy) trial, wherein the investigators found that, in line with other studies, adherence to all four recommended drugs was greater among polypill than usual care participants at 12 months ( $81 \%$ vs. $46 \%$; relative risk: 1.75 [95\% confidence interval: 1.52 to 2.03]; $\mathrm{p}<0.001)^{16}$. Thus, the therapeutic effectiveness of polypill in secondary prevention of CVD is well supported with quite a few clinical studies. However, the clinical rationale of usage of a polypill in primary prevention of CVD is still under investigation. The role of polypills in the primary prevention of CVD is still less clear.

Essentially, the rationale for promoting the usage of polypill is straightforward. viz., improving adherence to treatment, availability, and efficiency. Thereby expecting that the polypill might serve as a strategy to improve risk factor control and ultimately decrease CV events on a global scale ${ }^{2}$. The largest benefits are seen in those who are under-treated at baseline, rather than those who are already taking the individual components separately: simplified step-up is more important than pill count reduction ${ }^{11}$.

There are impressive, potential benefits that come with the use of a polypill strategy in CV prevention. Unfortunately, the use of a polypill for $\mathrm{CV}$ prevention is relatively novel, and although data from clinical trials are accumulating, the clinical question that remains to dissipate skepticism is whether the polypill, beyond improving adherence and risk factor control as surrogate markers, can significantly reduce CV events ${ }^{2}$. Although emerging data will help refine indications for the polypill. At present, there is no consensus regarding which patient population the polypill should be prescribed. Physicians like to have the flexibility to titrate individual agents and, as a result, are often hostile to the concept of fixed-dose combination or polypills. Thus, considerable efforts are needed for altering the physician's practice. Also, patient acceptability is an important criterion for widespread polypill usage. This will largely depend upon the number of pills to be taken, the dosing frequency and interval, and whether the pill is easy to swallow, considering the size of the tablet, and can be taken with food and drink-and the occurrence of side effects ${ }^{16}$. Another critical skepticism is that patients will regard the polypill as anexcuse to potentially replace efforts to promote healthy lifestyles. The reasoning is that if patients assume an overvalued outlook on the polypill that will protect them from exposure to all CV risk factors, they may feel that they have the freedom to adopt inappropriate lifestyles without consequences ${ }^{2}$.

Further, it is very critical to understand that not all drugs are suitable for use in combination products. Ideally, the candidate agents should be safe, well-tolerated, effective in sub-maximal doses, and physiochemically compatible with the other components of the pill ${ }^{16}$. A positive linear relationship has been seen between the number of active components in polypill and the rise in technical problems of formulation development along with a likely increase in drug interactions ${ }^{4}$. This could eventually affect the bio-availability and/or efficacy of the drugs. In theory, a combined single tablet of multiple generic drugs should be cost-effective. However, the individual agents are often substantially more expensive and pharmaceutical development and registration cost would substantially increase the cost of polypill ${ }^{16}$.

Thus, overall, the selection of individual components that are pharmaceutically compatible, doses, formulation type, and regulatory issues present unique challenges in the pharmaceutical development of a CV polypill. Therefore, a polypill needs to balance between pharmacological galenic challenges and its clinical usefulness ${ }^{4}$. Possible pros and cons of the polypill therapy in CVD are enlisted in Tablel.

Table l: Pros and Cons of the polypill therapy in CVD ${ }^{16}$

\begin{tabular}{|c|c|c|}
\hline Sr. & Pros & Cons \\
\hline 1 & $\begin{array}{l}\text { Growing general } \\
\text { professional and } \\
\text { healthcare support for the } \\
\text { polypill }\end{array}$ & $\begin{array}{l}\text { Concerns regarding the size } \\
\text { of the pill that might result in } \\
\text { patient non-acceptance and } \\
\text { eventually results in patient } \\
\text { non-compliance. }\end{array}$ \\
\hline 2 & $\begin{array}{l}\text { Recognition that the } \\
\text { individual titration of each } \\
\text { component (as in many } \\
\text { guidelines) does not work } \\
\text { on grounds of cost and/or } \\
\text { practicality }\end{array}$ & $\begin{array}{l}\text { Pharmaceutical } \\
\text { incompatibility amongst the } \\
\text { component } \\
\text { drugs might result in poor } \\
\text { bioavailability and reduced } \\
\text { efficacy or even side effects }\end{array}$ \\
\hline 3 & $\begin{array}{l}\text { Costs are expected to be } \\
\text { lower than individual } \\
\text { drugs }\end{array}$ & $\begin{array}{l}\text { Need for testing of the } \\
\text { efficacy of the combination } \\
\text { drugs }\end{array}$ \\
\hline 4 & $\begin{array}{l}\text { Patient compliance and } \\
\text { convenience }\end{array}$ & $\begin{array}{l}\text { Need for multiple sizes of the } \\
\text { polypill for flexibility in } \\
\text { dosing }\end{array}$ \\
\hline 5 & $\begin{array}{l}\text { Easier for the elderly to } \\
\text { understand the dosing }\end{array}$ & $\begin{array}{l}\text { Need for several types of } \\
\text { polypills in order to cover } \\
\text { different patient profiles, } \\
\text { e.g. post } \\
\text { MI/hypertension/diabetes/ch } \\
\text { ronic heart failure, etc. }\end{array}$ \\
\hline 6 & $\begin{array}{l}\text { Ensures that all the } \\
\text { evidence-based medicines } \\
\text { are given, bypassing the } \\
\text { likelihood that general } \\
\text { practitioners might miss } \\
\text { one or more components }\end{array}$ & Regulatory constraints \\
\hline 7 & $\begin{array}{l}\text { Potentially very large } \\
\text { public health benefits at } \\
\text { affordable cost, e.g. } \\
\text { generic statins }\end{array}$ & $\begin{array}{l}\text { Doses of the individual drugs } \\
\text { in a polypill may be best for } \\
\text { a general population, but } \\
\text { less optimal for an individual } \\
\text { patient }\end{array}$ \\
\hline
\end{tabular}

\section{CONCLUSION}

The use of polypills can significantly improve the use of effective CVD medications and, thereby, reduce the global burden of cardiovascular events. However, it may be necessary to produce different versions of the polypill with varying components, and concentrations of the different drugs, to address the implicit lower flexibility of the polypill with respect to dose modification of its individual components. Also, it needs to be ensured that the combination of drugs in the polypill are bio- compatible and efficacious. Though in the current scenario, lack of clearly defined regulatory paths and market failure in funding affordable medicines has hampered efforts to make polypills widely available for use in clinical practice. It is expected that in the future, a balanced and clear regulatory approach of regulatory bodies for the approval and bigger clinical trials of polypill combinations, will result in the potentially large public health benefits from the affordable combinations of well-proven therapies.

\section{REFERENCES}

1. Chow CK. Polypills for primary prevention of cardiovascular disease. Nature Reviews Cardiology. doi:10.1038/s41569-019-0209-y

2. Castellano JM, Sanz G, Peñalvo JL, et al. A polypill strategy to improve adherence. Journal of the American College of Cardiology. 2014;64(20):20712082. doi:10.1016/j.jacc.2014.08.021

3. World Health Organization. Secondary prevention of non-communicable disease in low and middle income countries through community-based and health service interventions. In: Wellcome Trust Meeting Report, August 1, Geneva: World Health Organization, 2002. ; 2002:1-3.

4. Singh K, Salam A, Devarajan R, Patel A, Prabhakaran D. Polypill (fixed-dose combination) in the prevention of cardiovascular disease: rationale and 
clinical data. Clinical Investigation. 2012;2(12):1213-1229. doi:10.4155/

cli.12.127

5. Cimmaruta D, Lombardi N, Borghi C, Rosano G, Rossi F, Mugelli A. Polypill, hypertension and medication adherence : The solution strategy? International Journal of Cardiology. Published online 2017:1-6. doi:10.1016/ j.ijcard.2017.11.075

6. López-jaramillo P, González-gómez S, Zarate-bernal D, et al. Polypill : an affordable strategy for cardiovascular disease prevention in low - mediumincome countries. Published online 2018:169-174. doi:10.1177/https

7. Law MR, Wald NJ RAR. Quantifying effect of statins on low density lipoprotein cholesterol, ischaemic heart disease, and stroke: systematic review and meta-analysis. BMJ. 2003;326:1423-6.

8. Law MR Wald NJ, Morris JK JRE. Value of low dose combination treatment with blood pressure lowering drugs: analysis of 354 randomized trials. BMJ. 2003;326:1427-35.

9. Wald NJ LMR. A strategy to reduce cardiovascular disease by more than $80 \%$. BMJ. 2003;326:1419-1422.

10. Webster R, Rodgers A. Polypill treatments for cardiovascular diseases. Exper Opinion on Drug Delivery. 2016:13(1):1-6. doi:10.1517/17425247.2016.1111869

11. Malekzadeh F, Marshall T, Pourshams A et al. A pilot double-blind randomised placebo controlled trial of the effects of fixed-dose combination therapy ('polypill') on cardiovascular risk factors. Int J Clin Pract. 2010; 64:1220-7.

12. PILL Collaborative Group, Rodgers A PA, Berwanger O et al. An international randomised placebo- controlled trial of a four-component combination pill ("polypill") in people with raised cardiovascular risk. PloS One. 2011;6:e19857.

13. Yusuf $\mathrm{S}$, Pais $\mathrm{P}$, Sigamani A et al. Comparison of risk factor reduction and tolerability of a fulldose polypill (with potassium) versus low-dose polypill (Polycap) in individuals at high risk of cardiovascular diseases: The second Indian Polycap Study (TIPS-2) investigators. Circ Cardiovasc Qual Outcomes. 2012;5:463-71.

14. Thom S, Poulter N, Field J et al. Effects of a fixed-dose combination strategy on adherence and risk factors in patients with or at high risk of CVD: the UMPIRE randomized clinical trial. JAMA. 2013;310:918-29.

15. Selak V, Elley CR, Bullen C et al. Effect of fixed dose combination treatment on adherence and risk factor control among patients at high risk of cardiovascular disease: randomised controlled trial in primary care. BMJ. 2014;348:g3318.

16. Sleight $\mathrm{P}$, Pouleur $\mathrm{H}$, Zannad F. Benefits, challenges, and registerability of the polypill. European Heart Journal. 2006;27(14):1651-1656. doi:10.1093/ eurheartj/ehi841 